\title{
Yiqi-yangyin-jiedu Herbal Decoction
}

National Cancer Institute

\section{Source}

National Cancer Institute. Yiqi-yangyin-jiedu Herbal Decoction. NCI Thesaurus. Code C132026.

A traditional Chinese medicine (TCM) based formulation consisting of milkvetch root, glehnia root, asparagus root, lilyturf root, grossy privet fruit, spikemoss herb, Chinese sage herb, and manyleaf paris rhizome, with potential immuno-enhancing, detoxifying and antineoplastic activities. Upon administration, yiqi-yangyin-jiedu decoction (YYJD) may activate the immune system by enhancing T-lymphocyte activity, and inhibiting tumor cell proliferation. YYJD may also ameliorate the qi-yin deficiency syndrome by strengthening qi and nourishing yin. YYJD may help remove toxic substance. 